SSCL --321

DE91 006353

\title{
IMPLEMENTATION OF ONE-TURN MAPS IN SSCTRK USING ZLIB
}

\author{
S. K. Kauffmann, Y. T. Yan \\ Superconducting Super Collider Laboratory ${ }^{\dagger}$ \\ 2550 Beckleymeade Ave. \\ Dallas, TX 75237
}

and

D. M. Ritsún

Stanford Linear Accelerator Center*

P.O. Box 4349

Stanford, CA 94305

Septernber 1990

\section{DISCLAIMER}

\begin{abstract}
This repcrt was prepared as an account of work sponsored by an agency of the United States Government. Neither the United States Government nor any agency thereof, nor any of their employees, makes any warranty, express or implied, or assumes any legal liability or responsibility for the accuracy, completeness, or usefulness of any information, apparatus, product, or process disclosed, or represents that its use would not infringe privately owned rights. Reference herein to any specific commercial product, process, or service by trade name, trademark, manufacturer, or otherwise does not necessarily constitute or imply its endorsement, recommendation, or favoring by the United States Government or any agency thereof. The views and opinions of authors expressed herein do not necessarily state or reflect those of the United States Government or any agency thereof.
\end{abstract}

\footnotetext{
Toperated by the Universities Research Association, Ine, for the U.S. Department of Energy under Contract No. DE-AC()2-89ER40486.

* Under contract with the U.S. Department of Energy, Contract No. DE-ACO2-76SF()(0515.
} 


\title{
Implementation of One-Turn Maps in SSCTRK using ZLIB
}

\author{
S. K. Kauffmann, Y. T. Yan, and D. M. Ritson
}

SSC Laboratory, 2550) Beckleymeade Avenue, Dallas, Texas 75237

\begin{abstract}
The particle tracking code SSCTRK is currenlly being adapted to operational simulation and hean-beam effect studies for the Collider rings of the SSC. During beam-beam effect studies, the lattice conten! of the bending arcs is normally not varied, making fast truncated Titylor map tracking through the ares an attractive option. The implementation of SSCTRK as a truncated Taylor map tracking progman has been carried out using the differential algebra library ZLIB, which simplified the task to that of straightforward translation of SSCTRK kick and drift arithmetic operations to calls to the corresponding polynomial operation subroutines of ZLIB. The accuracy and speed (relative to normal SSCTRK tracking) of truncated Taylor map tracking at $2 \mathrm{~mm}$ betatron oscillation anplitude was studied in various orders of the map. The seventh order map was found to be in agreement with the nomal SSCIRK to about eight signifieant tigures on the lirst turn, and to a fraction of $1 \%$ on the 100,000 th turn, for a typical $5 \mathrm{~cm}$ magnet aperture lattice, and could be made to track at ten times the speed of the normal SSCTRK kick-drift tracking on a scalar architecture (Sun) workstation. (The map tracking subroutines of ZLIB are optimized for vector and parallel architecture supercomputers, and typically achieve even faster relative performanec on these, but operational simulation studies will be more conveniently carried out on dedicated workstations which have the incoming generation of "superscalar" (PUs.)
\end{abstract}

\section{Introduction}

The differential algebra library ZLIB' offers analytic multivariable polynomial manipulation and truncated Tayfor map tracking which permil accelerator Taylor map construction, tracking and analysis to be carried out with case and efficiency under the tramework of an IMSL-style wser library. ZLIB is divided into two sublibraries, ZPLIB and TPALIB. ZPLIB is oriented toward speed and efficiency on vectorizing or parallelizing (multitasking) supercom siters, while the more straightforward subroutines of TPALIB generally nun a little faster on scalar architecture conpulers. The fast, thin-concatenated-element, kick-drift tracking code SSCTRK (written for the purpose of tracking proton beams through the Collider rings of the SSC) is in the process of being reconfigured for operational simulation and beam-beam elfect studies in the SSC, 10 be carried catt on very last, dedicated workstations which have the incoming generation of "supersealar" CPUs. As it is ustal to bold the lattice content of the bending ares tixed during beam-beam effect simmlation studies, hast tracking with a fruncated Taylor map) hrongh those ares at a maximum betatron oscillation amplitude of about $2 \mathrm{~mm}$ is felt to be an attractive option. Below we discuss the translation of the kick-drift tracking section of SSCTRK into onc-lum truncated Taylor map) consenction code through use of the ZLIB sublibrary TPALIB, with the commented code itself being given

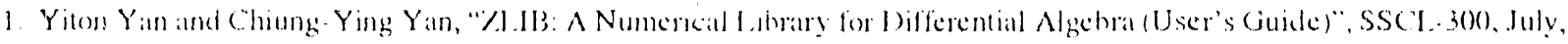
1990 . 
In Appendix A. Code for the analogous transiation through use of the ZPLIB sublibrary of ZLIB is given in Appendix $B$. The accuracy of the varous map truncation orders is evaluated vis-a-vis the correspondme SSCTRK kick-idrilt results at $2 \mathrm{~mm}$ betatron oscillation anplitude over $1(X),(K)$ ) turns for a typical SSC $5 \mathrm{~cm}$ magnet aperture lattice, and the speed advantage of the aeceptably accurate seventh order map on a scalar CPU (Sun) workstaion over the original SSCTRK kick-drift code is presented.

\section{Translation of SSCTRK kick-drift tracking to Taylor maps using ZLIB}

Unlike the post-TEAPOT tracking program Ztrack, which contains hundreds of statements and involves square roots and trigonometric functions, ${ }^{2}$ the kick-drift tracking section of SSCTRK, consisting of just a few dozen lines of highly optimized, simple code which involve essentially only additions and multiplications, allows economic implementation of onc-turn maps. With the help of the ZLIB User's Guide (footnote 1), these arithmetic operations are straightforwardly translated into calls to ZLIB subroutines which perfom the corresponding polynomial operations. For example, the basic (FORTRAN coded) vertical kick in SSCTRK,

$P H=P H-R I G I T Y * I M P O L$.

translates to one polynomial multiplication subroutine call to the TPALIB sublibrary of ZLIB, followed by one polynomial subtraction subroutine call to that sublibrary,

CALL TFAMUL(FRIG,FIMPOL,FTMPO,5) followed by CALL TPASUB(FPH,FTMPO,FPH,NM) .

Notice that the polynomial FRIG corresponds to the guantity RIGITY, the polynomial FIMPCL corresponds to the gulantity IMPOL, and the polynomial FPH corresponds to the vertical betatron oscillation angle PH. In addiition, we store the intermediate result corresponding to the "kick" product RIGITY*IMPOL in the cemporary polynonial FTMPO, which, in the second call, is subtracted from the polynomial FPH to "kick update" it. "The last argument " 5 " of the call to subroutine TPAMUL above is the number of variables of which all of our polynomals are functions, while the last argument NM of the call to subroutine TPASUB above is the mumber of linearly independent terms in each of our polynomials (this is detemined by their number of variables, i.e., 5, and their common order -. note liat TPAMUL above will tnoncate its polynomial multiplication result FTMPO to that common order NO, which needs to have been previously specified in an initial call to the TPALIB "preparation' subroutine TPAPRP(5,NO,NM)).

Nol every guantity occurring in the kick-drift tracking section of SSCTRK is translated into a polynomial. Any guantity which remains fixed - ".n-by-tum around the Collider is treated as a constant in the polynomial algebra. Thus the basic SSCTRK vertical drift,

$Y=Y+L O^{*} P H$,

contains the fixed drift length LO, which is treated as a constant rather than a polynomial. Of course, the vertical betatron oscillation displacement $Y$ and angle PH are treated as polynomials FY and FPH (all such polynomials are represented in the FORTRAN code as single-index, double-precision arrays of length NM, while the monstants are represented as just double-precision unindeved variables). This basic vertical drift is taken care c. by a single TPALIB subroutine call which simply updates the polynomial FY as the appropriate linear combination of FY and $\mathrm{FPH}$,

CALL TFALIN(FY,LO,FPH,FY,NM)

We conld mandge to do with polyomials of tive variables rather than the general accelerator physics set of six

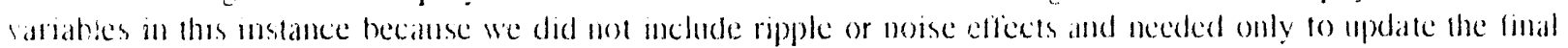

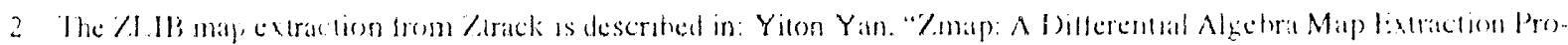

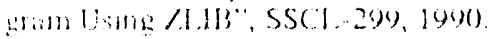


longitudinal displacement after a fill worn through the ares and RF cavity by an additive term which doesn't depend at all on the intial tongitudinal displacement (we dich't acmally include the RF cavity in our polynomial mapping of the arcs, as it would have cost accuracy for a neglighte saving of tracking time). Since the variables of which our polymonials are functions correspond to the irredecible set of tum-by-turn varymg initial values at the beginning of each turn, we can effectively drop the longitudinal displasement as such a varbable. The change in the longitudinal displacement is, however, calculated as a polyomial depending on the other variables becanse its value after one turn through the aress is needed by the RF cavity section of the code. The momentum displacement, on the other hand, must be counted as a variable even though it doesn't change at all in the ares -- it undergoes a conplicated change on every furn in the RF cavity. The remaining four variables are, of course, the vertical and horizontal betatron oscillation displacements and angles. The TPALIB subroutine TPAPOK 1 (polyn, const, var no, NM) initializes polyn as const tires the variable associated with var no, which indexes the initial value array that is to be used for map tracking. Thus, after initializing T PAL.IB with CALL TPAPRP(5,NO,NM), we initialize those polynomials which are to begin the map tracking turn as one of the five pure variables having values equal to those of the appropriately indexed members of the initial value array XINPT, e.g.,

CALL TPAPOK1(FX,1.OD+0,1,NM); CALL TPAPOK1(FTH, 1.0D+0,2,NM);

and also

CALL TPAPOK $1($ FY, 1.OD+0,3,NM); CALL TPAPOK $1(F P H, 1.0 D+0,4, N M) ; C I C$.

The initial value array for the begimning of the turn is FORTRAN dimensioned as XINPT(5), and the above statements will initialize the polynomial FX to a particular unit coefficient first-order monomial which will have the value XINPT (1) at the begimning of the turn, the polynomial FTH to another unit coefficient first-order monomial which will have the val'a XINPT(2) at the beginning of the turn, the polynomial FY to yet another unit coefficient first-order monomial which will have the value XINPT(3) at the beginning of the turn, the polynomial FPH to yet a fourth a unit coefficient first-order monomial which will have the value XINPT(4) at the begiming of the turn, etc.

From the above examples of code we see that the translation of the tracking section of SSCTRK into a polymomial mapping through the use of the TPALIB sublibrary of ZLIB was relatively straightorward and intuitive. The full code produced is given in Apsendix $A$ (in the map construction subroutine OPSTPA, the original kick-drift code statements from SSCTRK subroutunes OPSTRK and PTRACK are given in commented lines just before their translation into TPALIB subroutine calls), which it may be instructive to sludy in conjunction with the readIng of the ZLIB User s unide. Two "unoficial" modified TPALIB routmes were incorporated into the code, the map writeout (to a file) routine WTPKMAP and the specialized map tracking routine TPKMTRK5, which sacrifices generality in the number of variables and the number of output polynomials (both frozen at five) for maximum map tracking speed. Analogous code for translation using the ZPL!B sublibrary of ZLIB is given in Appiendix B.

\section{Cornparison of the ZLIB translated map tracking with SSCTRK itself}

The one-turn tnuncated Taylor map consunction code given in Appendix A lent itself to a precise check tor the correctness of the map in the special case of a purely linear lantec the number of multipoles PPOLES $=1$, the relative momentum offset DELP:-(), and the RF voltage PRFV()=0(), in the language used in subroutunes OPSTPA and PRFACC, given in Appendix $A$ ). In this instance the results of lise first-order one-furn map agreed precisely (essenthally to all the digits of the double-precision accuracy used) with the results of the original SSCTRK kickarift code when tracked through a single tum. Thus perfect correlation of the pureiy lineat lattice w th the corresponding first-order map for one lurn is a tescful consistency check for the correctness of mapping transtations arred ont with the aid of ZLIB.

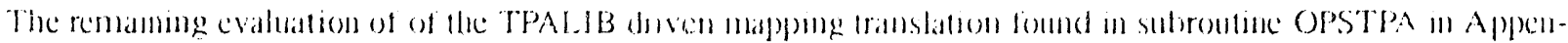

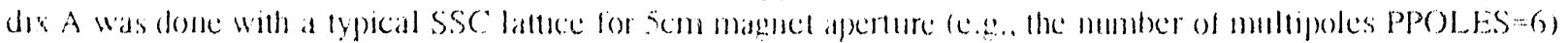


with a realistic value for the relative momentum offset DELP $\left(5 \times 10^{-4}\right)$, and the RF voltage turned on. All tracking was done with the invariant horizontal and vertical amplitudes each initialized at 2 mm, and various truncation orders of the map were compared with the original SSCTRK kick-drift code resull over 10(0,0)( 1 (urns. Typically, the combined horizontal-vertical invariant (which is not sensitive to horizontal-vertical compling) avcraged over 5000 turns was monitored. Under these circumstances the second order map bethaved unaceptably, with its 5000-turn-averaged combined horizontal-vertical invariant increasing at an accelerating pace with turn number (ihis invariant was essentially constant for the original SSCTRK kick-drift code), and the particle leaving the beam tube aperature entirely before it had gone 20,000 turns. The third-order map behaved much more reasonably, though it displayed rather the opposite behavior from the second oder map -- the horizontal-vertical invariant tended to become smaller with tum number rather than remain constant as it ought to have (in accord with the original SSCTRK kick-drift code behavior), i.e., the particle spiraled inward (see Figure 1). Figure 1 indicates the fourth-order map to have substantially the same behavior as the third-order map, albeit marginally worse. The fifth-order map was a vast improvement (again see Figure 1) and the sixth-order map again showed marginal deterioration realative to the fifth-order (both are sufficiently good that this is hard to follow on Figure 1 without a magnifying glass). This odd-even order "great improvement - marginal deterioration" was a consistent feature of the lattice we were testing at $2 \mathrm{~mm}$ betatron oscillation amplitudes, but likely was a peculiarity of that lattice rather than a general property of truncaled Taylor maps. The "great improvement" of the seventh order map was sufficient to bring the combined horizontal-vertical invariant within one part in 20,000 of that of the original SSCTRK kick-drift code, which difference cannot be resolved within the thickness of the line in Figure 1. Further, on the 100,000 th tum itself the horizontal betatron oscillation was still faithful within a fraction of one percent to that of the original SSCTRK kick-drift code, from which the map had, of course, been translated. (After the first turn, the agreement in borizontal betatron oscillation is to about eight significant figures.)

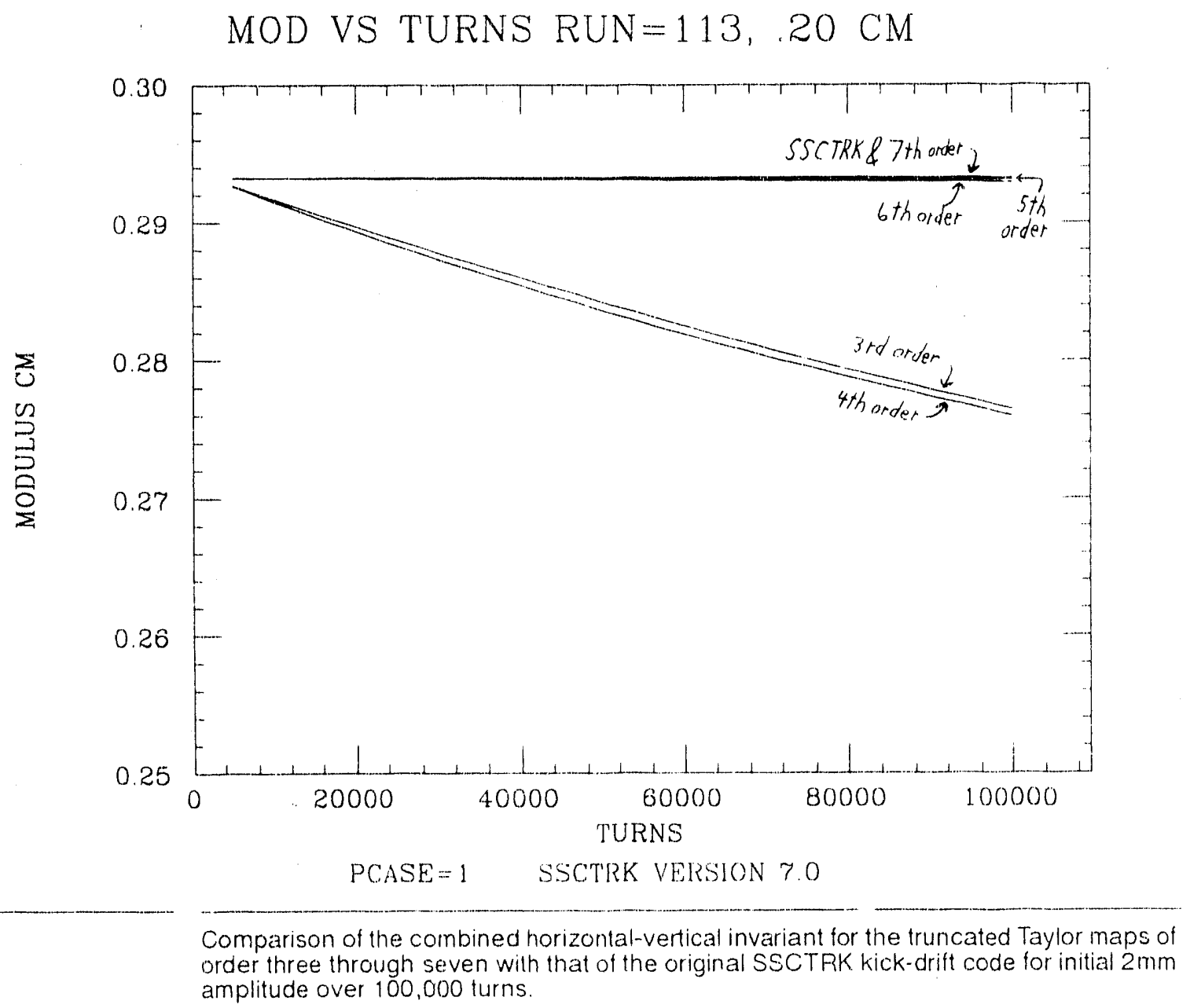

\section{FIGURE 1} order three through seven with that of the original SSCTRK kick-drift code for initial $2 \mathrm{~mm}$ amplitude over 100,000 turns 
This very acceptably accurate (for use with the bending ares in beam-beam effect simulation studies) seventh-or(ler map executed a factor of ten faster on the scalar architecture Sun workstation than did the original SSCTRK kick-drift code when the special purpose map) tracking subroutine TPKMTRK5 was used. Subroutine TPKMTRK5, presented in Appendix $A$, is related to the subroutine TPAMTRK of TPALIB, but sacrifices generality in the number of inputs and outputs (with both frozen at five) to speed. On supercomputers the corresponding subroutines from ZPLIB (see Appendix B), which are optimized for vectorization and multitasking (parallelization), conld be expected to have an even greater relative speed advantage.

\section{Conclusion}

This use of ZLIB to effect the translation of the tracking section of the SSCTRK kick-(lrift codle to mapping construction and map tracking code shows that ZLIB is indeed a user-friendly, effective, and efficient way to build and track truncated Taylor maps. The uni(pue and powerful vectorization and parallelization features of ZLIB (in the sublibrary ZPL_BB) were not used in this particular application, nor were ZLIB's map analysis features, but the easy-to-use, familiar (from its IMSL-like framework), and efiticient features of ZLIB made this mapping application one that was easily and quickly carried out. 
Appendix A

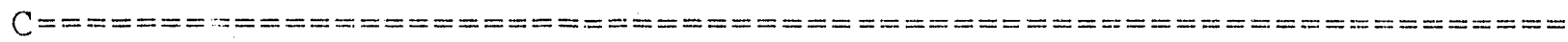

SUBROUTINE OPSTPA(IER)

C SIMPLIFIES, TRACKING CONTROL FOR SINGLE LATTICE, MULTIPLE COORD

C NO RANDOM GENERATOR CALLS ARE MADE SO THAT SEEDOO IS NOT CHANGED

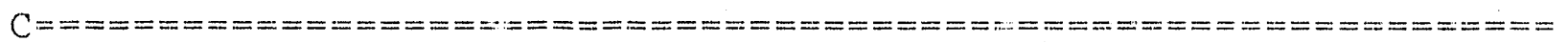

INCLUDE 'header'

INTEGER* 4 J, NLIST, LIST (MAXCAS), IER, V

INTEGER * 4 NO, NM, IJMR, KK, I

LOGICAL* 4 ONLYTR

COMMON /ONLTR/ ONLYTR

CHARACTER * 4 JOBID

COMMON /JBID/ JOBID

$\mathrm{C}=====\mathrm{NO}$ IS MAP POLYNOMIAL ORDER; SINCE THERE ARE 5 POYNOMIAL VARIABLES,

$\mathrm{C}=====$ NM EQUALS $(\mathrm{NO}+5) ! /(5 ! *$ NO!), THE POLYNOMIAL ARRAY LENGTH

PARAMETER ( $\mathrm{NO}=7, \mathrm{NM}=792)$

$\mathrm{C}=====$ POLYNOMIAL VARIABLES (ARRAYS) USED IN MAPPING - THEY ARE MAINLY

$\mathrm{C}=====$ THE CORRFSHONDING SSCTRK VARIABLE NAMES WITH LETTER F PREFIXED;

$\mathrm{C}=====$ ALSO THE OUTPUT MAP VARIABLE (ARRAY SSCMP) AND THE INPUT AND OUPUT

$\mathrm{C}=====$ ARRAYS FOR THE MAP TRACKING (ARRAYS XINPT \& YOUTP)

FEAL* 8 FX(NM),FTH(NM),FY(NM),FPH(NM),FZMZI(NM),FKIDLP(NM),

$+\quad$ FK2DLP(NM),FK3DLP(NM),FRIG(NM),FREPOL(NM),FIMPOL(NM),

$+\quad \operatorname{FRETMP}(\mathrm{NM}), \operatorname{FIMTMP}(\mathrm{NM}), \operatorname{FTMPO}(\mathrm{NM}), \operatorname{XINPT}(5)$,

$+\quad \operatorname{YOUTP}(5), \operatorname{SSCMP}(\mathrm{NM}, 5)$

$\mathrm{C}=====\mathrm{THE}$ OUTPUT MAP VARIABLE (ARRAY SSCMP) - EQUIVALENCED TO THE FIVE

$\checkmark=====$ POLYNOMIAL OUTPUT VARIABLES

EQUTVALENCE $(\operatorname{SSCMP}(1,1), \operatorname{FX}(1)),(\operatorname{SSCMP}(1,2), \operatorname{FTH}(1))$,

$+\quad(\operatorname{SSCMP}(1,3), \operatorname{FY}(1)),(\operatorname{SSCMP}(1,4), \operatorname{FPH}(1)),(\operatorname{SSCMP}(1,5), \operatorname{EZMZI}(1))$

$I E R=0$

IF (PCASES.EQ.O) THEN

PRINT' *, 'XXX NO PCASES XXXX'

$I E R=-I$

RETURN

ENDIF

WRITE $(2,501)$ 89, PCASES

501 EORMAT ( I 2, I3, I3, I 4, I 8, 5G12.5)

NLIST $=$ PCASES

DO $10 \mathrm{~V}=1$, MAXCAS

LTST $(V)=V$

$\operatorname{STEP}(V)=0$ 
10 CON'IINUE

$C=====$ INITIALIZE TPALIB FOR MAPPING;

$C=====$ NO INITIALIZATION NEEDED FOR TRACKING ONLY

IF (. NOT, ONLYTR) THEN

CALL TPAPRP (5, NO, NMR)

$\mathrm{C}=========$ PROTECTION : CONSISTENCY OF NM WITH NMR

IF (NM.NE.NMR) THEN

PRINT*, ${ }^{\prime} N M=', N M, ', N M R=', N M R, ', X X$ OPSTPA ERROR XX'

$I E R=-1$

RETURN

ENDIF

ELSE

$\mathrm{C}=====I \mathrm{~F}$ TRACKING ONL"?, READ IN MAP FROM FORTRAN UNIT 1 AND

$\mathrm{C}-====$ SKIP THE MAPPING SECTION

CALL RTPAMAP (SSCMP, 1, 5, NM, 1)

PRINT*,' $\mathrm{NO}={ }^{\prime}, \mathrm{NO},{ }^{\prime}, \mathrm{NM}=1, \mathrm{NM}$

ENDIF

GO TO 200

$\mathrm{C}=====$ MAPPING SECTION (TPALIB TRANSLATION FROM OPSTRK \& PTRACK) FOLLOWS;

$\mathrm{C}=====$ POLYNOMIALLY TRANSLATED SSCTRK VARIABLES HAVE LETTER F PREFIXED

$\mathrm{C}=====$ INITIALIZE $\mathrm{X}, \mathrm{TH}, \mathrm{Y}, \mathrm{PH}$ MAP INPUT VARIAB́LES

CALL TPAPOK1 ( $E X, 1 . O D+0,1, N M)$

CALL TPAPOK $1($ ETH $, 1.0 \mathrm{D}+0,2, \mathrm{NM})$

CALI TPAPOK1 ( $F Y, 1 . O D+0,3, N M)$

CALL TPAPOK.1 (EPH, 1.OD+0,4, NM)

$C====$ INITIALIZE ZMZI (Z MINUS Z INITIAL) MAP OUTPUT VARIABLE TO ZERO

CALL TPAZRO (FZMZI, NM)

$\mathrm{C}=====$ INITIALIZE MAP INPUT VARIABLES RELATING TO DELP:

$\mathrm{C}=====\mathrm{K} \perp \mathrm{DELP}(\mathrm{V})=\mathrm{K} 1 * \mathrm{DELP}(\mathrm{V})$

CALL TPAPOK1 (FKIDLP, K.1, 5, NM)

$\mathrm{C}=====\mathrm{K} 2 \mathrm{DELP}(\mathrm{V})=\mathrm{K} 2 * \mathrm{DELP}(\mathrm{V})$

CALI TPAPOK1 (FK2DLP, K2, 5, NM)

$\mathrm{C}====-\mathrm{K} 3 \mathrm{DELP}(\mathrm{V})=\mathrm{K} 3 * \mathrm{DELP}(\mathrm{V})$

CALL TPAPOK1 (FK3DLP, K3, 5, NM)

$\mathrm{C}=====\operatorname{RIGITY}(\mathrm{V})=1 . \mathrm{D}+0 /(1 . \mathrm{D}+0+\mathrm{DELP}(\mathrm{V}))$

CALL TPAPOK 1 (FRIG, 1.OD+0,5, NM)

CALL TPACADD ( $1.0 \mathrm{D}+0$, FRIG, FRIG, NM)

CALL TPAINV (FRIG, FRIG, 5)

$C=====$ INITIALIZATIONS ARE DONE. CREATE MAP BY TRANSLATING DTRACK. DO $100 \quad \mathrm{KK}=1$, POLELS

$C===:=====x \operatorname{REPOL}(\mathrm{V})=0 . \mathrm{D}+0$

CALL 'TPAZRO (FREPOL, NM)

$C==\cdots======$ IMPOL $(V)=0 . D+0$

CALL TPAZRO(ETMPOL, NM)

DO $120 \quad \mathrm{I}=$ PPOLES $, 1, \cdots 1$

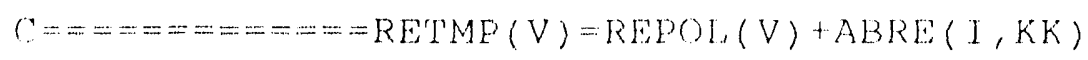


CALL TPACADD (ABRE(I, KK), FREPOL, FRETMP, NM)

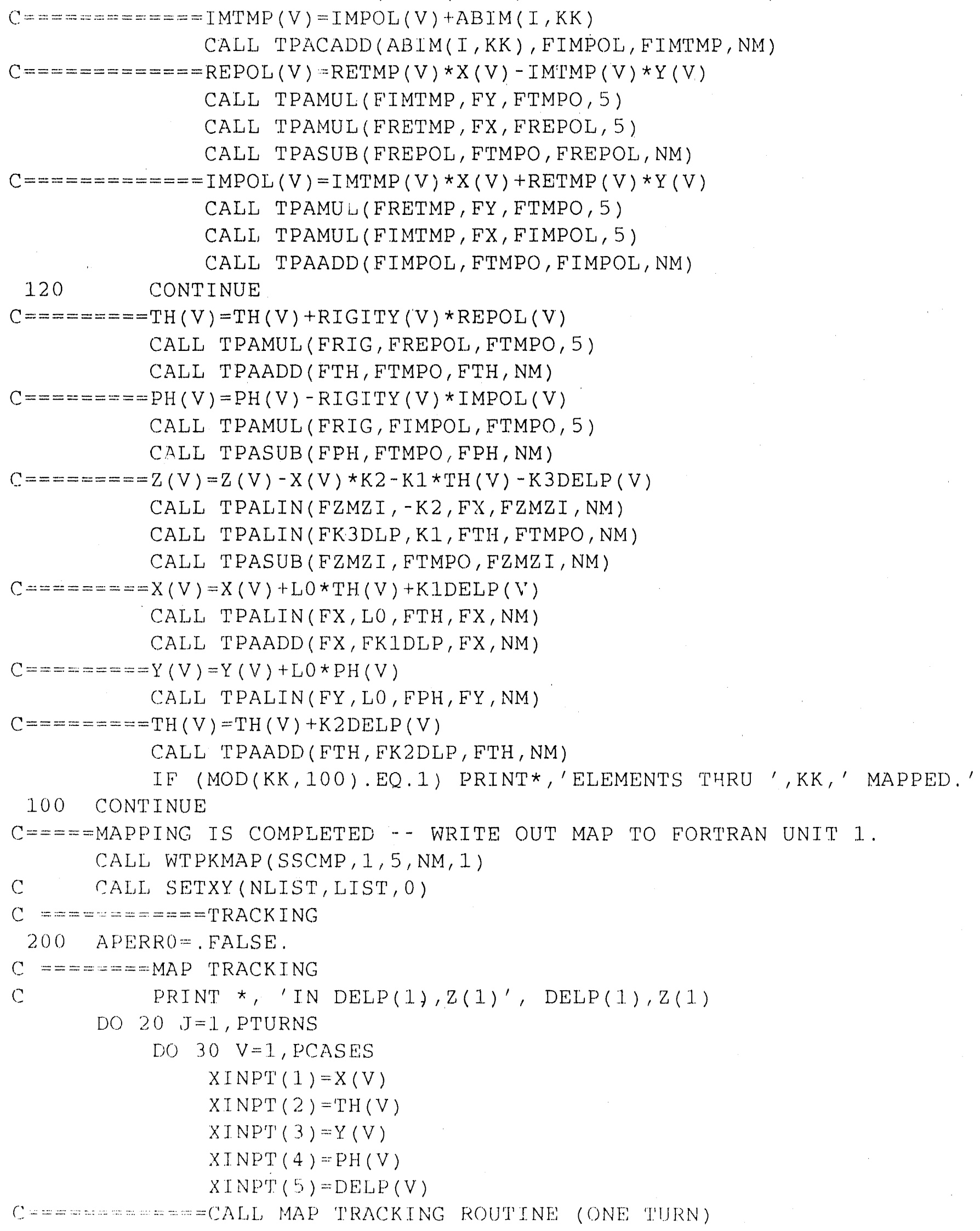


CALL TPKMTRK5 (SSCMP, NO, XINPT, YOUTP, NM)

$$
X(V)=\operatorname{YOUTP}(1)
$$

$\mathrm{TH}(\mathrm{V})=\mathrm{YOUTP}(2)$

$Y(V)=\operatorname{YOUTP}(3)$

$\mathrm{PH}(\mathrm{V})=\mathrm{YOUTP}(4)$

30

$Z(V)=Z(V)+Y O U T P(5)$

C IF PARTICLES LEAVE APERTURE THE JUBROUTINE RETURNS

$I E R=0$

NLIST $=0$

CALL PCHEK(NLIST, LIST, J)

IF (APERRO) THEN

A.PERRO = . FALSE.

$I E R=1$

PRINT *, 'OUTSIDE APERTURE'

RETURN

ENDIF

C DISPERSION FREE COORDINATES AT RF CAVITY

DO $50 \mathrm{~V}=1$, PCASES

C DISPERSION FREE COORDINATES AFTER HALF QUAD THEN DISPERSTON CORR

C IF TRACK IS REVERSED THEN SIGN OF TWISS MUST CHANGE BEFORE AND

C AFTER PRFACC IN XOUT STATEMENTS

$\operatorname{THOUT}(\mathrm{V})=\mathrm{TH}(\mathrm{V})+\mathrm{QD} / 2 . * \mathrm{X}(\mathrm{V})$

$\operatorname{PHOUT}(V)=\mathrm{PH}(\mathrm{V})-\mathrm{QD} / 2 * \mathrm{Y}(\mathrm{V})$

$\operatorname{XOUT}(V)=X(V)-\operatorname{TWISS}(3,1,1) * \operatorname{DELP}(V)$

$\mathrm{YOUT}(\mathrm{V})=\mathrm{Y}(\mathrm{V})$

$\mathrm{C}$

$50 \quad$ CONTINUE

WRITE $(2, *) \quad J, Y O U T(V), \operatorname{XOUT}(V)$

C CALL PRFACC ADDS RF CAVITY ACCELERATION AND ADIABATIC DAMPING TERM

CALL PRFACC

DO $60 . \mathrm{V}=1$, PCASES

C DISPERSED COORDINATES AFTER DISPERSION AND $-1 / 2$ QUAD

$X(V)=X O U T(V)+\operatorname{TWISS}(3,1,1) * \operatorname{DELP}(\mathrm{V})$

$\mathrm{Y}(\mathrm{V})=\mathrm{YOUT}(\mathrm{V})$

$\mathrm{TH}(\mathrm{V})=\mathrm{THOUT}(\mathrm{V})-2 \mathrm{D} / 2 \cdot * \mathrm{X}(\mathrm{V})$

$\mathrm{PH}(\mathrm{V})=\mathrm{PHOUT}(\mathrm{V})+\mathrm{QD} / 2 * \mathrm{Y}(\mathrm{V})$

60 CONTINUE

20 CONTINUE

PRINT *, 'OPSTPA: X1, THL, P1, Z1', X(1),TH(1), DELP(1), Z(1)

RETURN

F.ND

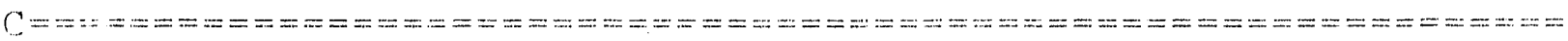

SUBROUTINE PCHEK(NLIST, LIST, iJ) 
C THIS SUBROUTINE CHECKS FOR PARTICLES EXCEEDING THE BEAM TUBE APERTURE.

C RETURNS APERRO=(.GT.APERTURE LIMIT), NLIST=NUMBER OF PARTICLES

C OUTIDE APERTURE ON THIS TURN AND LIST $(V)=C A S E$ NUMBERS

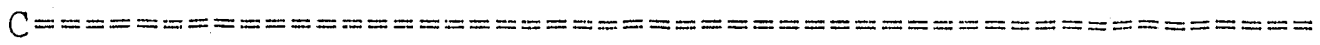

INCLUDE 'header'

INTEGER* 4 V,NLIST, LIST (MAXCAS), J

LOGICAL* 4 APERR (MAXCAS)

REAL * 8 EMITV(MAXCAS), SQAP, THDUM(MAXCAS), PHDUM(MAXCAS),

$+\quad$ APX, APTH, APPH, SMEMT (MAXCAS)

REAL* 4 RMSEMT (MAXCAS)

COMMON /SUMEMT/ SMEMT

$\operatorname{APX}=\operatorname{TWISS}(2,1,2) / \operatorname{TWISS}(2,1,1)$

APTH $=$ APX $* \operatorname{TWISS}(2,1,1) * * 2$

APPH $=\operatorname{TWISS}(2,2,1) * * 2$

$S Q A P=2 * A P L I M * * 2$

APEREO $=$. FALSE.

$C=====-=== \pm===$ CHECK WITH VECTORIZED LOGIC IF PARTICLE IS $>$ APLIM

DO $10 \mathrm{~V}=1$, PCASES

$\operatorname{THDUM}(\mathrm{V})=\mathrm{TH}(\mathrm{V})+\mathrm{QD} / 2 \cdot \mathrm{D}+\mathrm{O} * \mathrm{X}(\mathrm{V})$

$\operatorname{PHDUM}(\mathrm{V})=\mathrm{PH}(\mathrm{V})-\mathrm{QD} / 2 * \mathrm{Y}(\mathrm{V})$

$\operatorname{EMITV}(\mathrm{V})=\mathrm{APX} * \mathrm{X}(\mathrm{V}) * * 2+\mathrm{APTH} * \operatorname{THDUM}(\mathrm{V}) * * 2+\mathrm{Y}(\mathrm{V}) * \star 2+$

- $\mathrm{APPH} * \mathrm{PHDUM}(\mathrm{V}) * * 2$

$C========$ ACCUMULATE EMITV FOR EVERY TURNS, THEN PRINT IT OUT AS AN

$C=========$ RMS AND ELUSH CUT THE ACCUMULATOR.

IF (J.EQ.1) $\operatorname{SMEMT}(V)=0.0 \mathrm{D}+0$

$\operatorname{SMEMT}(V)=\operatorname{SMEMT}(V)+\operatorname{EMITV}(V)$

IF (MOD (J,EVERY).EQ.0) THEN

$\operatorname{RMSEMT}(V)=\operatorname{SQRT}(\operatorname{SMEMT}(V) / \operatorname{EVERY})$

$\operatorname{SMEMT}(\mathrm{V})=0.0 \mathrm{D}+0$

ENDIF

WRITE $(2, *) J, V, \operatorname{RMSEMT}(\mathrm{V})$

10 CONTINUE

DO $15 \mathrm{~V}=1$, PCASES

$\operatorname{APERR}(V)=(\operatorname{EMITV}(\mathrm{V}) \cdot \mathrm{GT} . \mathrm{SQAP})$

15 CONTINUE

DO $20 \mathrm{~V}=1$, PCASES

$\operatorname{APERRO}=(\operatorname{APERRO} \cdot \mathrm{OR} \cdot \operatorname{APERR}(\mathrm{V}))$

20 CONTINUE

$C===========$ LABEL IF PARTICLE(S) OUTSIDE LIMIT

IF (APERRO) THEN

DO $30 \mathrm{~V}=1$, PCASES

IF (APERK(V)) THEN

NLIST $=$ NLIST +1

$\operatorname{LIST}(\operatorname{NLIST})=\mathrm{V}$

EINDI F

30

CONTI NUE 
ENDIF

RETURN

END

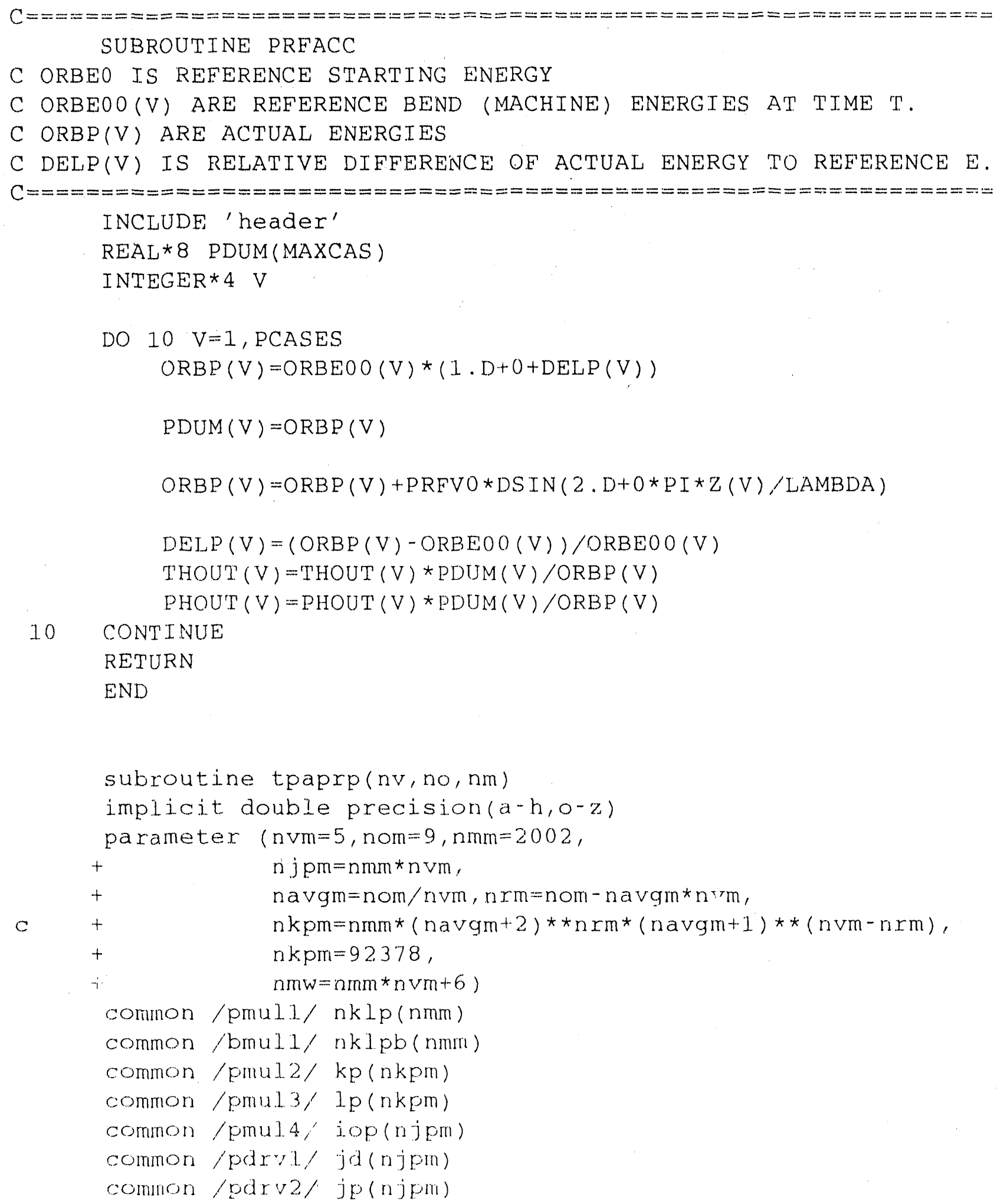


common /parv3/ jo(njpm)

common /mulwk/ wkmul (nmm)

common /divwk/ whdivinmw)

comnon /conwk/ work (nmw)

call tpa626 (nv, no, nkm, nmw, nken, njpm,nm)

return

end

subroutine wtpkmap (uu, nub, nue, nm, imap)

implicit double precision(a-h,o-z)

dimension uu(nm, nue)

do $10 \mathrm{i}=$ nub, aue

writie(inap, *) 'variable $=$ ', i

do $10 \quad j=1, \mathrm{~nm}$

write (imap, *) $\left.u^{\prime}: j, i\right)$

10

continue

return

end

subroutine tpkmtrk5(au, nou, $, 7 y, n m)$

implicit double precision $(a-h, 0-z)$

parameter $(n u=5, n \%=5$, nomax $=26)$

dimension wu(nm, $n u), x(n \%), r(n u)$

dimension monomax, n?

do $10 \quad i=1,01$

$\because: i ;=0 . d+0$

10 cortinue

$j=0$

$x *(0,5)=1, d+0$

do $20 \quad+5=0, \mathrm{nou}$

$x(j 5-1,5)=2(5) * x(j 5,5)$

$n+4=n 01-j 5$

$x x(0,4)=x x(35,5)$

$9029+9=0.24$

$x \times(j+1,4)=x(4)+x \times(j 4,4)$

na $=n+-94$

$x+3,=x x(5+4)$

io 20 j $3=0, n$

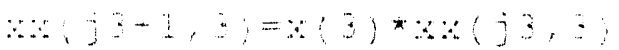

$n a=n-3$

$\because \cdots, \cdots, \cdots, 3,3)$

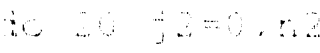

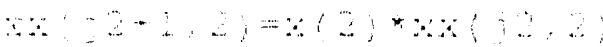

an $=n-2$ 


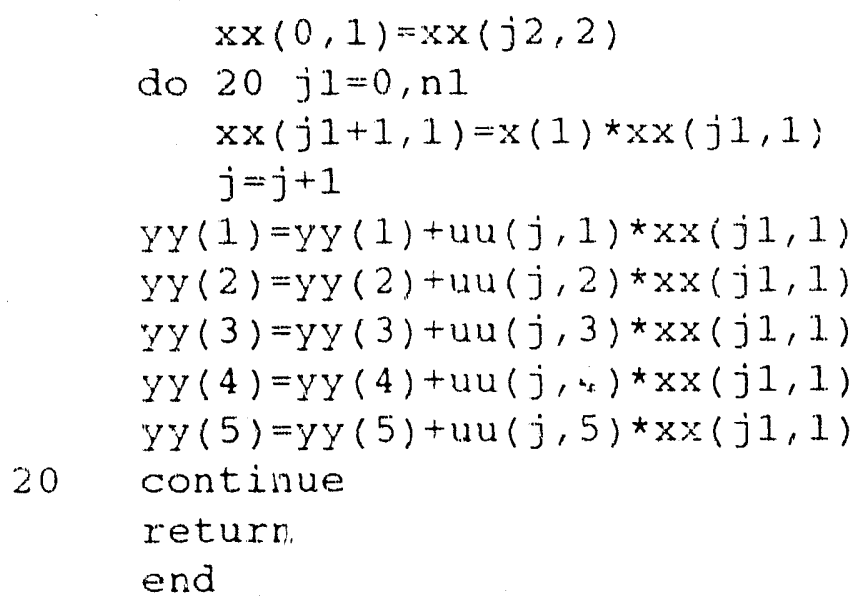




\section{Appendix B}

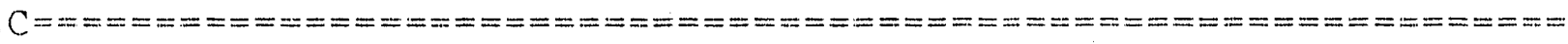

SUBROUTINE OPSMAP (IER)

C. SIMPLIFIED TRACKING CONTROL FOR SINGLE LATTICE, MULTIPLE COORD

C NO RANDOM GENERATOR CALLS ARE MADE SO THAT SEEDOO IS NOT CHANGED

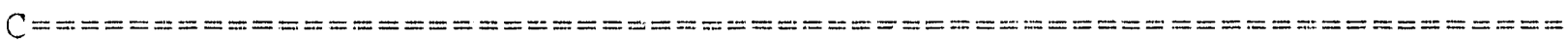

INCLUDE 'header'

INTEGER*4 J, NLIST, LIST (MAXCAS), IER, V

INTEGER*4 NO, NM, NMR, NOK, KK, I

LOGICAL* 4 ONLYTR

COMMON /ONLTR/ ONLYTR

CHARACTER * 4 JOBID

COMMON /JBID/ JOBID

$\mathrm{C}=====N$ IS MAP POLYNOMIAL ORDER; SINCE 'L'HERE ARE 5 POYNOMIAL VARIABLES,

$\mathrm{C}=====$ NM EQUALS $(\mathrm{NO}+5) ! /(5 ! *$ NO!), THE POLYNOMIAL ARRAY LENGTH

PARAMETER $(\mathrm{NO}=7, \mathrm{NM}=792)$

$C====$ POLYNOMIAL VARIABLES (ARRAYS) USED IN MAPPING - - THEY ARE MAINLY

$C====$ THE CORRESPONDING SSCTRK VARIABIE NAMES WITH LETTER F PREFIXED;

$C====A L S O$ THE OUTPUT MAP VARIABLE (ARRAY SSCMP) AND THE INPUT AND OUPUT

$C====$ ARRAYS EOR THE MAP TRACKING (ARRAYS XINPT \& YOUTP)

REAL* 8 FX(NM),FTH(NM),FY(NM),FPH(NM),FZMZI(NM), EKIDLP(NM),

+ $\quad$ EK2DLP(NM), FK3DLP(NM),FRIG(NM), FREPOL(NM),FIMPOL(NM),

$+\quad \operatorname{RETMP}(\mathrm{NM}), \operatorname{FIMTMP}(\mathrm{NM}), \operatorname{FTMPO}(\mathrm{NM}), \operatorname{XINPT}(5)$,

$+\quad \operatorname{YOUTP}(5), \operatorname{SSCMP}(\mathrm{NM}, 5)$

$\mathrm{C}====\mathrm{THE}$ OUTPUT MAP VARIABLE (ARRAY SSCMP) - EQUTVALENCED TO THE FIVE

$C=====$ POLYNOMIAL, OUTPU'T VARIABLES

EQUIVALENCE $(\operatorname{SSCMP}(1,1), \operatorname{FX}(1)),(\operatorname{SSCMP}(1,2), \operatorname{FTH}(1))$,

$+\quad(\operatorname{SSCMP}(1,3), \operatorname{Fy}(1)),(\operatorname{SSCMP}(1,4), \operatorname{FPH}(1)),(\operatorname{SSCMF}(1,5), \mathrm{FZMZI}(1))$

$I E R=0$

IF (PCASES.EQ.O) THEN

ERINT *, 'XXX NO PCASES XXXX'

IER $=-1$

RETURN

ENDI $F$

WRITE $(2,501) 89$, PCASES

501 FORMAT (I2, I3, I3, I 4, I8, 5012.5)

NLIST $=$ PCASES

DO $10 \mathrm{~V}=1$, MAXCAS

$\operatorname{LIST}(\mathrm{V})=\mathrm{V}$

$\operatorname{STEP}(V)=0$ 
10 CONTINUE

$\mathrm{C}=====$ INITIALIZE ZPLIB FOR EITHER TRACKING ONLY OR ELSE MAPPING AS WELL IF (ONLYTR) THEN

CALL ZPTRKP ( 5, NO, 1, NMR)

ELSE

CALL ZPPREP(5, NO, 1, NMR)

ENDIF

$C=====$ PROTECTION: CONSISTENCY OF NM WITH NMR

IF (NM.NE, NMR) THEN

PRINT*,'NM = ',NM,', NMR =',NMR,', XXX OPSMAP ERROR XXXX'

$I E R=-1$

RETURN

ENDIF

$\mathrm{C}=====$ IF TRACKING ONLY, READ IN MAP FROM FORTRAN UNIT 1 AND

$\mathrm{C}=====$ SKIP THE MAPPING SECTION

IF (ONLYTR) THEN

CALL RDMAPZP(SSCMP, 5, NO, 1)

GO TO 200

ENDIF

$C====$ MAPPING SECTION (ZPLIB TRANSLATION FROM OPSTRK \& PTRACK) FOLLOWS;

$\mathrm{C}=====$ POLYNOMIALLY TRANSLATED SSCTRK VARIABLES HAVE LETTER F PREFIXED

$C=====$ INITIALIZE $X, T H, Y, P H$ MAP INPUT VARIABLES

CALL ZPOK1(FX,1.OD+0,1, NM)

CALL ZPOK1. (FTH, 1.OD+0,2, NM)

CALL ZPOKL (FY, 1.OD+0,3, NM)

CALL ZPOKI (FPH, 1.OD+0,4, NM)

$C=====$ INITIALIZE ZMZI (Z MINUS Z INITIAL) MAP OUTPUT VARIABLE TO ZERO

CALL ZPZRO(EZMZI, NM)

$C===\pi$ INITIALIZE MAP INPUT VARIABLES RELATING TO DELP:

$C=====K 1 D E L P(V)=K 1$ *DELP $(V)$

CALL ZPOKI (FKIDLP,K1, 5, NM)

$\mathrm{C}=====-\mathrm{K} 2 \mathrm{DELP}(\mathrm{V})=\mathrm{K} 2 * \mathrm{DELP}(\mathrm{V})$

CALL ZPOK1(FK2DLP, K2, 5, NM)

$C=====K 3 D E L P(V)=K 3 \star D E L P(V)$

CALL ZPOK1 (EK 3DLP, K3, 5, NM)

$C=====\operatorname{RIGITY}(V)=1 . D+0 /(1 . D+0+D E L P(V))$

CAILL ZPOKI (FRIG, I.OD+0,5, NM)

CALI ' $\angle P C A D D(1 . O D+0, F R I G, F R I G, N M)$

CALL ZPINV(FRIG, NO, FRIG, NO)

C.:- INITIALIZATIONS ARE DONE. CREATE MAP BY TRANSLATJNG PTRACK.

DO $100 \mathrm{KK}=1$, POLELS

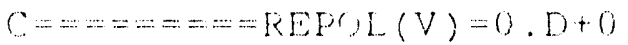

CALL ZPZRO(FREPOL, NM)

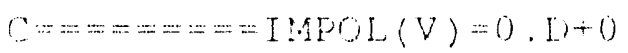

CALL ZPZRO(FIMPOL, NM)

DO $120 \quad I=$ PPOLES, $1,-$ ? 


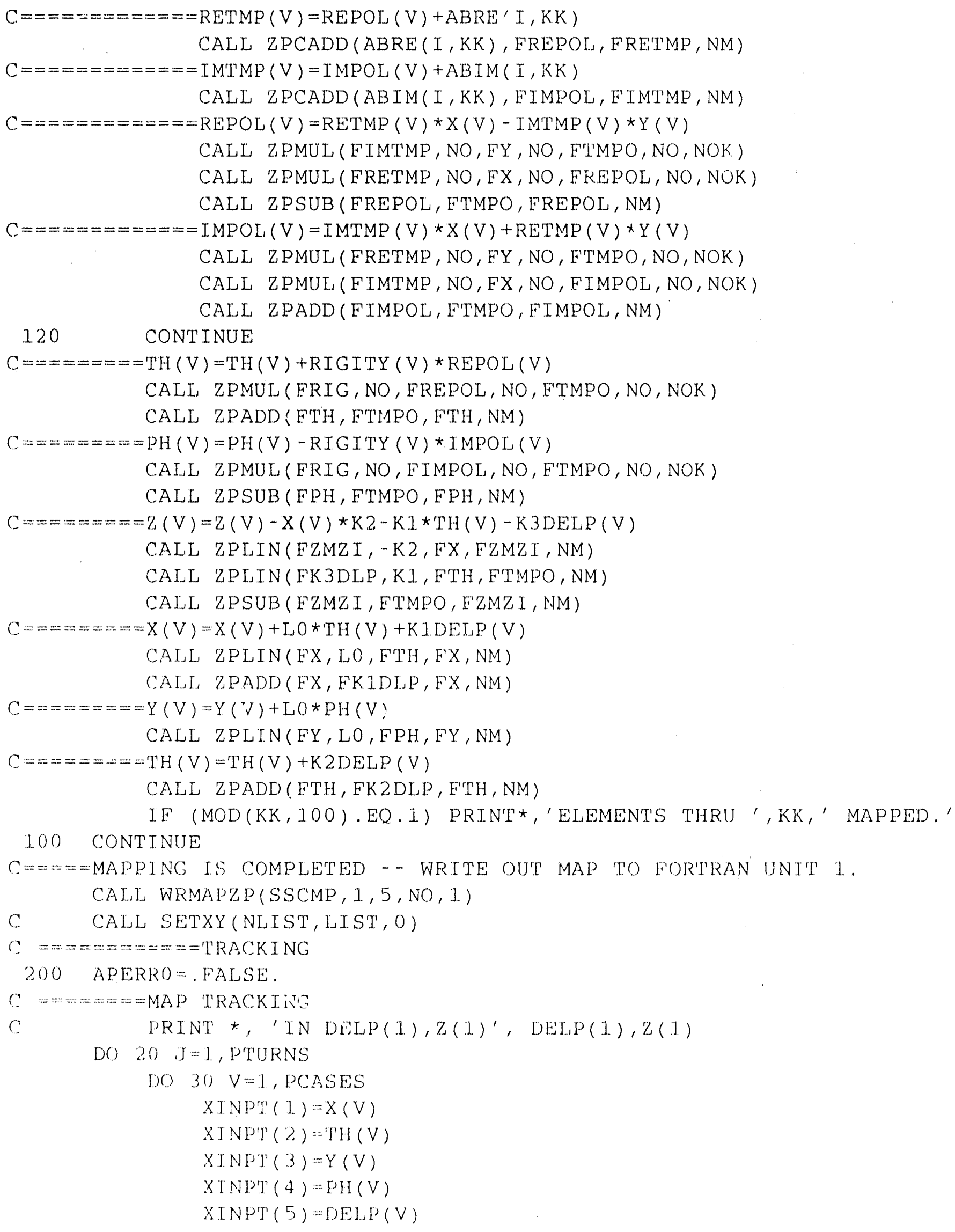




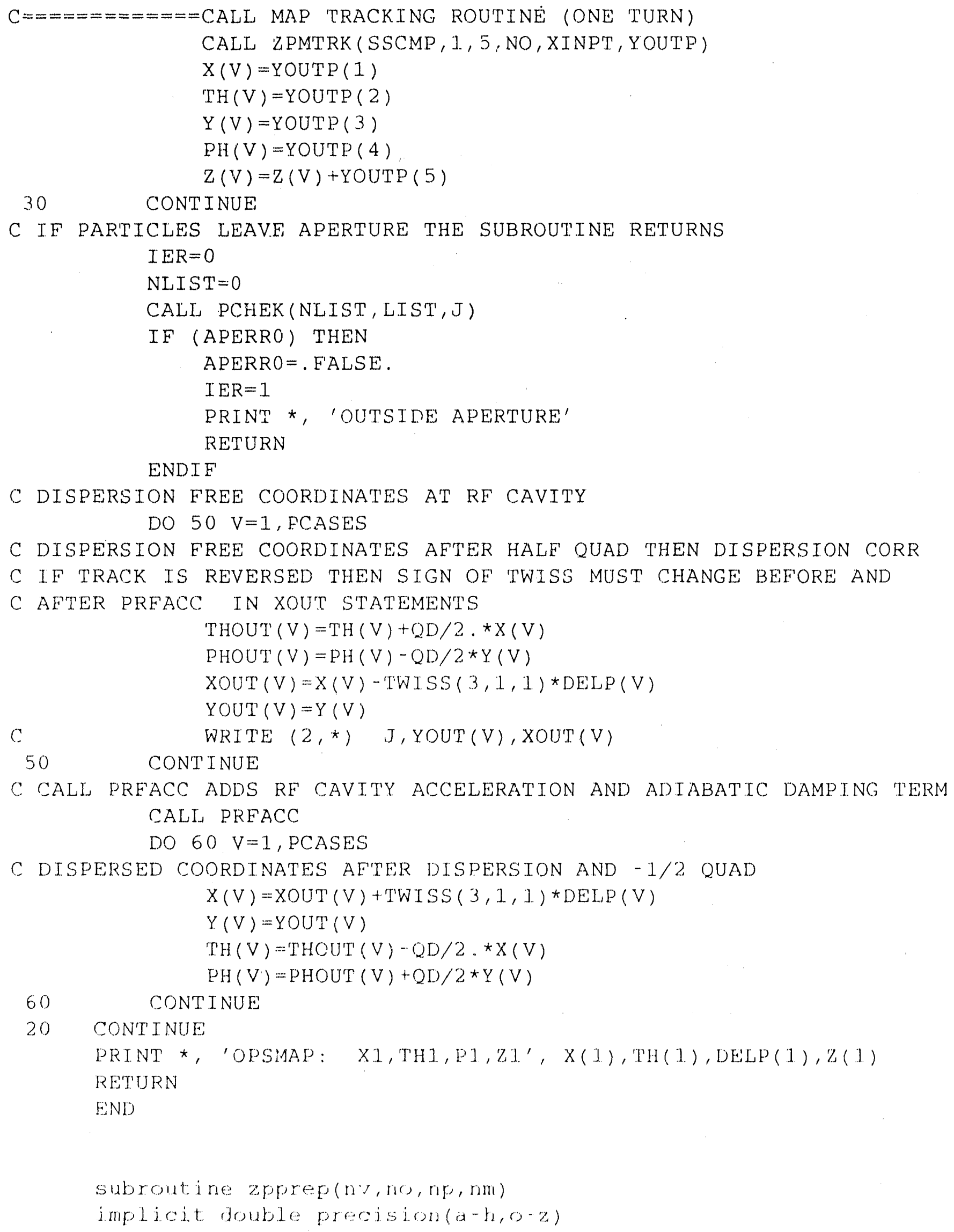




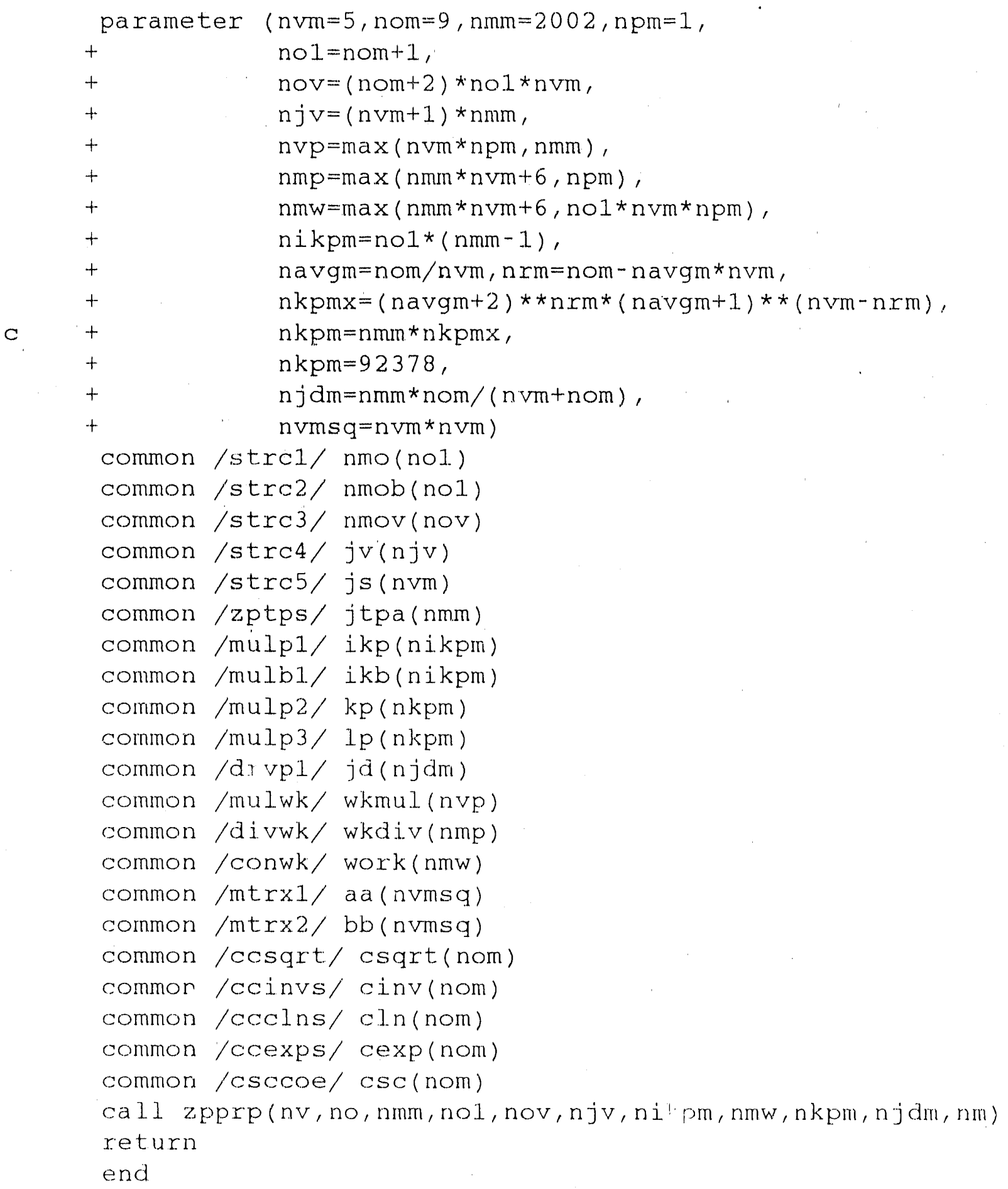




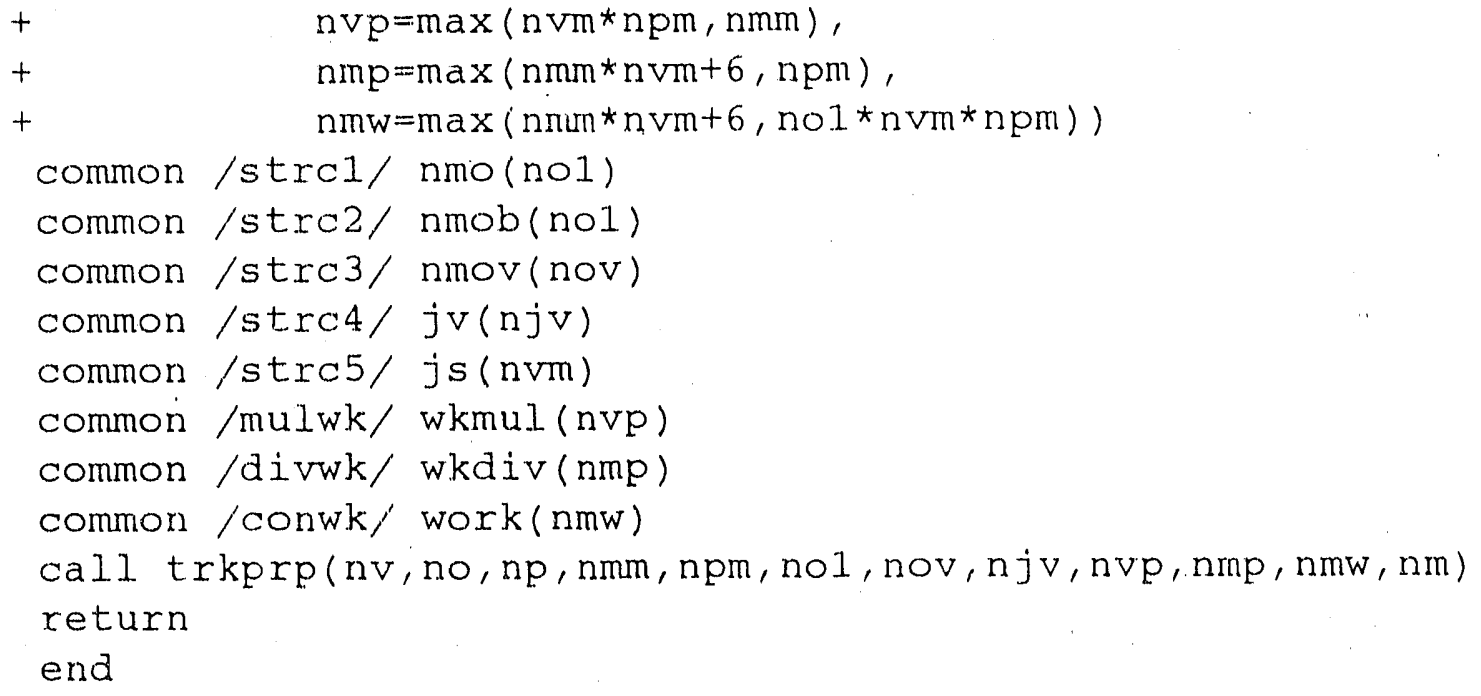



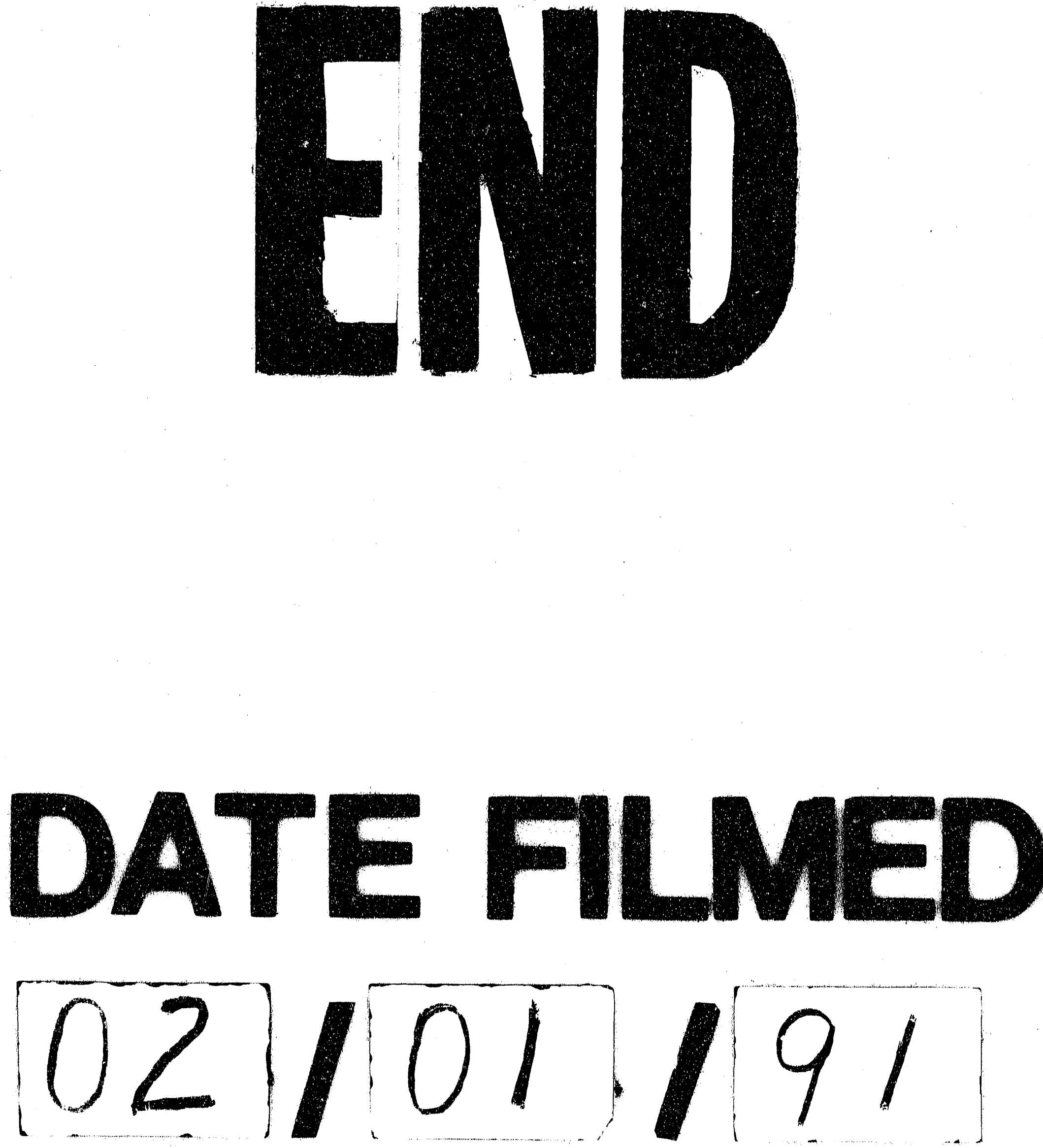
